\title{
Permissive effects of thyroid hormones on rat anterior pituitary mitotic activity
}

\author{
L A Nolan, C K Thomas and A Levy
}

Henry Wellcome Labs for Integrative Neuroscience and Endocrinology, University of Bristol, Dorothy Hodgkin Building, Whitson St, Bristol BS1 3NY, UK

(Requests for offprints should be addressed to L Nolan; Email: Lesley.a.Nolan@bristol.ac.uk)

\begin{abstract}
The anterior pituitary is active mitotically and apoptotically under basal conditions and in response to a variety of physiological and pathophysiological stimuli. Hypothyroidism in man is associated with a modest but very occasionally dramatic increase in overall pituitary size. The mechanisms underlying this reversible phenomenon remain obscure. In the present study we have examined young adult rat anterior pituitary following surgical thyroidectomy and subsequent thyroid hormone treatment and withdrawal using an extremely accurate system for quantifying directly identified mitotic and apoptotic events. Despite the expected increase in the number and/or proportion of immunohistochemically identifiable thyrotrophs three weeks after thyroidectomy, mitotic and apoptotic activity remained unchanged, as did pituitary wet weight, in comparison with sham-operated and intact controls. In contrast, mitotic but not apoptotic activity was enhanced by treatment of thyroidectomized animals with thyroid hormones (triiodothyronine $\left(\mathrm{T}_{3}\right)$ and thyroxine $\left(\mathrm{T}_{4}\right) 1.8 \mu \mathrm{g}$ and $3.6 \mu \mathrm{g} / 100 \mathrm{~g}$ body weight per day respectively), and once again declined to levels seen in intact animals within $72 \mathrm{~h}$ of subsequent thyroid hormone withdrawal. Thyroid hormone-induced enhancement of mitotic activity was also seen in intact rats treated with similar doses of thyroid hormones for 7 days and in
\end{abstract}

thyroidectomized rats treated for a similar period with very low dose thyroid hormone replacement at a level that had no effect on raised hypothalamic TRH- or pituitary TSH $\beta$-transcript prevalence $(0.018 \mu \mathrm{g} \mathrm{T}$ 佂 $0.036 \mu \mathrm{g}$ $\mathrm{T}_{4} / 100 \mathrm{~g}$ body weight per day). Thus changes in mitotic and apoptotic activity are unlikely to be the principle mechanism for the apparent increase in thyrotrophs up to 4 weeks after thyroidectomy. In contrast, the data indicate that thyroid hormones have a permissive effect on anterior pituitary mitotic activity in thyroidectomized male rats. Thyroid hormone-induced enhancement of mitotic activity in intact rats further suggests that in euthyroid rats, ambient thyroid hormone levels are a limiting factor for anterior pituitary mitotic activity. In summary, this time course study of young, male rats has shown for the first time that thyroidectomy, thyroid hormone replacement and subsequent withdrawal has no significant effect on anterior pituitary apoptotic activity. Secondly, it has shown that the anterior pituitary mitotic response to thyroidectomy is blocked by complete thyroid hormone deprivation, but can be restored by very low level thyroid hormone replacement, and thirdly that in intact animals thyroid hormone levels significantly limit anterior pituitary mitotic activity.

Journal of Endocrinology (2004) 180, 35-43

\section{Introduction}

The adult pituitary gland is mitotically and apoptotically active under basal conditions and able to respond rapidly and repeatedly to specific stimuli such as adrenalectomy and timed glucocorticoid replacement (Nolan \& Levy 2001, 2003). Modest pituitary enlargement is well described in human hypothyroidism and several case reports of pituitary enlargement sufficient to present with visual impairment through compression of the optic chiasm have been published (Ghannam et al. 1999, Brandle \& Schmid 2000, Nicholas \& Russell 2000, Kocova et al. 2001). Irrespective of the extent of pituitary enlargement, thyroid hormone replacement in the clinic appears to result in the rapid return of pituitary size to normal. A similar increase in pituitary size in chronic hypothyroidism (over several months) has been reported in rats although absolute changes in pituitary weight rather than pituitary weight relative to body weight tend to be small (Quintanar-Stephano \& Valverde 1997).

Several parenchymal cell subpopulations are thought to be involved in the pituitary mitotic response to hypothyroidism and thyroid hormone replacement (DeFesi et al. 1979, Quintanar-Stephano et al. 1999) and fluctuations in intracellular hormone levels that potentially cross immunohistochemical detection thresholds together with changes in relative cell size conspire to confound accurate, relative quantification (Levy \& Lightman 2003). Furthermore, the identification of the secretory subtype of cells unequivocally undergoing apoptosis is inherently insecure, 
and the potential for the absence of thyroid hormone to non-specifically inhibit mitotic activity must be taken into account (Ozawa \& Kurosumi 1993, Quintanar-Stephano \& Valverde 1997). Not surprisingly, the events that lead to the increase in relative pituitary size and subsequent resolution with treatment under these circumstances are not well understood.

We have previously described in detail the trophic responsiveness of the anterior pituitary to manipulation of the hypothalamo-pituitary-adrenal axis (Nolan et al. 1998, 1999, Nolan \& Levy 2001, 2003). In the current study, we have examined the time course of changes in the prevalence of anterior pituitary mitotic and apoptotic events in young, male Wistar rats following surgical thyroidectomy and relatively high dose thyroid hormone replacement and subsequent withdrawal. We have also examined the effects of very low dose thyroid hormone replacement in thyroidectomized rats (insufficient to affect raised thyrotrophin releasing hormone (TRH)- and thyroid-stimulating hormone beta (TSH $\beta$ )-transcript levels) and the effects of thyroid hormone treatment on mitotic activity in intact rats. Identification of these relatively rare events was achieved in thin haemotoxylin and eosin-stained tissue sections using well-defined morphological criteria, and quantified using a wellvalidated computerized aid to manual counting.

This study is the first to examine an extended time course of anterior pituitary mitotic responses to thyroidectomy, thyroid hormone replacement and subsequent withdrawal. It is also the first to simultaneously quantify the apoptotic responses of the anterior pituitary to these various stimuli. We have also explored the permissive effects of thyroid hormones in intact rats and of very low dose thyroid hormones in thyroidectomized animals.

\section{Materials and Methods}

\section{Animals and treatments}

All animal procedures were carried out in accordance with the UK Home Office animal welfare regulations. Male Wistar rats weighing between 100 and $125 \mathrm{~g}$ were purchased from Bantin and Kingman Universal Ltd (Hull, UK) and allowed to acclimatise for one week before being surgically thyroidectomized or sham-operated under anaesthesia with an intraperitoneal injection $(1 \mathrm{ml} / 100 \mathrm{~g}$ body weight $(\mathrm{BW})$ ) of a mixture of 2:2:2 tribromoethanol $(2 \% \mathrm{w} / \mathrm{v})$ in $100 \%$ ethanol $(8 \% \mathrm{v} / \mathrm{v})$ and 2 -methylbutan$2-\mathrm{ol}(1.2 \% \mathrm{v} / \mathrm{v})$ in $0.9 \%$ saline. Thyroidectomized rats were given $1 \%$ calcium chloride to drink after surgery.

At daily intervals beginning three weeks after surgery, groups of rats were given intraperitoneal injections of a mixture of $3,3^{\prime}, 5$-triiodo-L-thyronine $\left(\mathrm{T}_{3} ; 1.8 \mu \mathrm{g} / 100 \mathrm{~g}\right.$ BW per day; Sigma) and L-thyroxine $\left(\mathrm{T}_{4} ; 3.6 \mu \mathrm{g} / 100 \mathrm{~g}\right.$ BW per day; Sigma) in a final volume of $0.4 \mathrm{ml}$ saline. This dose is at least fourfold higher than that believed to be required to normalize circulating and tissue levels of thyroid hormones (Escobar-Morreale et al. 1996). One week after the start of treatment, further groups of thyroidectomized animals had thyroid hormones withdrawn for an interval of up to 6 days.

To examine whether the prevalence of mitotic cells is influenced by a combination of low circulating levels of thyroid hormones in the presence of increased endogenous $\mathrm{TRH}$, groups of thyroidectomized rats were given low doses of $T_{3} / T_{4}$ at daily intervals for 7 days starting immediately after surgery. Two doses of thyroid hormones were given: either $1.8 \mathrm{ng} \mathrm{T}_{3}$ plus $3.6 \mathrm{ng} \mathrm{T}_{4} / 100 \mathrm{~g} \mathrm{BW}$ per day (dose A: $0 \cdot 1 \%$ of the treatment dose used above), or $18 \mathrm{ng} \mathrm{T}_{3}$ plus $36 \mathrm{ng} \mathrm{T}_{4} / 100 \mathrm{~g} \mathrm{BW}$ per day (dose $\mathrm{B}$ : $1 \%$ of the treatment dose).

In order to follow cumulative changes in the number of recently divided anterior pituitary cells, additional groups of rats received daily intraperitoneal injections of bromodeoxyuridine (BrdU; $10 \mathrm{mg} / \mathrm{ml}$ in 0.007 M NaOH/0.9\% $\mathrm{NaCl}$; Roche) at a dose of $200 \mathrm{mg} / \mathrm{kg} \mathrm{BW}$. Injections were started on the day of thyroidectomy or sham surgery and continued for 7 days.

Groups of rats were killed by stunning and decapitation at intervals from $24 \mathrm{~h}$ to 4 weeks following either surgery or the start or withdrawal of thyroid hormone treatments. Animals were killed immediately after removal from their cages in a separate room adjoining that in which they had been housed. Animals subjected to surgical thyroidectomy were examined in each case to confirm complete excision. The number of animals at each time point was between 4 and 10 .

\section{Preparation of tissue sections}

Immediately after decapitation, brains were frozen on dry ice and pituitary glands were carefully removed, weighed and fixed in $4 \%$ formaldehyde in phosphate-buffered saline (PBS) for $48 \mathrm{~h}$, washed in two changes of fresh PBS and embedded in 1\% agar before being processed for paraffin wax embedding. A series of $2-\mu \mathrm{m}$ thick axial sections were cut from each pituitary for histological analysis and for in situ hybridization histochemistry to confirm the expected changes in TSH $\beta$ transcript levels. Coronal brain sections $(12 \mu \mathrm{m}$ thick) through the paraventricular nucleus were taken for TRH transcript quantification.

\section{In situ hybridization histochemistry}

In situ hybridization histochemistry was carried out as described (Levy \& Lightman 1988a) using ${ }^{35}$ S-dATP $3^{\prime}$-end-labelled synthetic 48 mer oligonucleotide probes complementary to either TRH $\left(2 \times 10^{5}\right.$ counts/slide $)$ or TSH $\beta\left(2 \times 10^{5}\right.$ counts/slide) mRNA (Shi et al. 1994). The resulting images were analysed densitometrically using the program NIH Image (NIMH, 
Bethesda, MD, USA) and results were expressed as the mean \pm standard error relative to controls ( $\% \pm$ S.E.).

TSH immunohistochemistry Pituitary sections were deparaffinized in xylene and rehydrated through a graded series of alcohols followed by incubation in $0 \cdot 1 \mathrm{M}$ phosphate buffer. Endogenous peroxidases were inactivated in phosphate buffer containing 20\% methanol, $0 \cdot 2 \%$ Triton $\mathrm{X}-100$ and $1 \cdot 5 \%$ hydrogen peroxide for $30 \mathrm{~min}$. Sections were blocked in 1\% normal goat serum and incubated overnight at $4{ }^{\circ} \mathrm{C}$ with rabbit anti-rat TSH serum (1/2000, Lot\# AFP1274789, kindly provided by Dr A F Parlow of the NIDDK). After washing in 3 changes of buffer, the sections were incubated for $90 \mathrm{~min}$ at room temperature with biotinylated anti-rabbit IgG (Vector Labs, Peterborough, Cambs, UK; 1/200 diluted in blocking serum). Following a further 3 washes in buffer, sections were incubated with biotinylated-streptavidin-horse radish peroxidase complex (1/200 in phosphate buffer; Amersham, UK) for $90 \mathrm{~min}$ at room temperature. Immunoreactive cells were visualized using the $3^{\prime}, 3^{\prime}$ diaminobenzidine (DAB) glucose oxidase method as described (Shu et al. 1988). The resulting brown colour reaction was stopped in water and sections were counterstained with haematoxylin.

BrdU immunohistochemistry Pituitary sections were processed for BrdU immunohistochemistry according to a previously published protocol with minor modifications (Cameron \& McKay 1999). Briefly, de-waxed and rehydrated sections were transferred to a hot antigen unmasking solution (0.01 $\mathrm{M}$ citric acid in water; $\mathrm{pH} 6 \cdot 0)$ and incubated for $10 \mathrm{~min}$ in a microwave oven on a power setting that maintained the solution just below its boiling point. Sections were then cooled in water to room temperature before permeabilizing for $10 \mathrm{~min}$ in $0.001 \%$ trypsin (Cat\# 210234, Lot\# 14986800, Roche, UK) diluted in $0 \cdot 1 \% \mathrm{CaCl}_{2} / 20 \mathrm{mM}$ Tris buffer ( $\left.\mathrm{pH} 7 \cdot 5\right)$. Following 3 washes in PBS, the slides were denatured in $2 \mathrm{M} \mathrm{HCl}$ in PBS for $30 \mathrm{~min}$, washed again in PBS, gently agitated for $20 \mathrm{~min}$ in blocking serum (3\% normal horse serum, $0.5 \%$ Triton X-100 in PBS) and incubated overnight at $4{ }^{\circ} \mathrm{C}$ with monoclonal clone B44 anti-BrdU antibody (Cat\# 347580, Lot\# 39497; BD Biosciences, Oxford, Oxon, UK; 1/100 diluted in blocking serum). Sections were washed in 3 changes of PBS, incubated for $1 \mathrm{~h}$ at room temperature with biotinylated anti-mouse IgG (Cat\# BA-2001, Vector Labs; 1/200 diluted in blocking serum), and washed again in fresh PBS before blocking endogenous peroxidases for $30 \mathrm{~min}$ with $0 \cdot 6 \%$ (v/v) hydrogen peroxide in PBS. Following a further 3 washes in PBS, sections were incubated with Vectastain Elite ABC reagent (Cat\# PK-7100; Vector Labs) for $30 \mathrm{~min}$ at room temperature, rinsed in PBS and developed for $8 \mathrm{~min}$ in DAB substrate according to the manufacturer's instructions (Cat\# SK-4100; Vector Labs). The resulting brown colour reaction was stopped in water and sections were counterstained with haematoxylin. The number of BrdU-labelled cells was expressed as a percentage of total cell numbers counted (BrdU-labelling index: $\% \pm$ s.E.).

\section{Image analysis for trophic activity}

Apoptotic, mitotic and BrdU-immunopositive cell counts were performed on $2 \mu \mathrm{m}$-thick haematoxylin and eosin $(\mathrm{H} \& \mathrm{E})$-stained rat pituitary sections at $1000 \times$ magnification with the aid of a dedicated real-time computer system to tag and tally the co-ordinates of manually identified trophic events within each tissue section (Nolan et al. 1998). The computerized Highly Optimized Microscope Environment (AxioHOME, Zeiss (Brugal et al. 1992)) that was used, projects a virtual image of the computer screen which appears fractionally above the actual microscope image and allows different markers to be laid down over apoptotic, mitotic or normal cells by hand as the stage is moved. The system retains a cumulative score of the numbers of each cell type counted, together with the co-ordinates of each individually marked cell irrespective of the position of the microscope stage or changes in power of the objective lens. Extremely accurate quantification of the various cell types is thus possible for each section studied, as areas can be circumscribed at low power (eliminating selection bias), and counted at high power without danger of double scoring.

The histological markers that were used to identify apoptotic cells were clusters of two or more apoptotic bodies consisting of extremely dense round or oval structures varying in diameter from approximately 0.7 to $4 \mu \mathrm{m}$ and surrounded by normal cells. Earlier stages of apoptosis cannot be visualised using $\mathrm{H} \& \mathrm{E}$ staining and light microscopy. For each animal, three random areas of approximately $47000 \mu^{2}$ were scored for the presence of mitotic and apoptotic figures. The error in quantifying the number of normal cells surrounding these events was $\leq 2 \%$.

TSH immunopositive cell counts were performed at $400 \times$ magnification. For each animal, four areas of approximately $75000 \mu \mathrm{m}^{2}$, each containing an average of 800 cells, were scored as positive or negative for the presence of immunoreactive TSH. No corrections were made for any changes in thyrotroph cell size that occur following thyroidectomy (Floderus 1944).

All slides were coded and counted by one observer (L A N) blinded to the treatments. Results were expressed as a percentage of the total cell numbers counted for each animal.

\section{Statistics}

Data were expressed as means \pm S.E. GraphPad Prism (GraphPad Software, San Diego, CA, USA) was used to perform statistical calculations. Differences between 
groups were evaluated using one-way ANOVA followed by Tukey-Kramer multiple comparison post-tests. $P<0 \cdot 05$ was considered statistically significant.

\section{Results}

\section{Thyroidectomy and thyroid hormone replacement efficacy}

Surgical thyroidectomy was associated with a consistent sixfold increase in both paraventricular TRH transcripts and anterior pituitary TSH $\beta$ transcripts $(P<0 \cdot 001, n=4-$ 6; Fig. 1a,b). No thyroid remnants were found in any of the thyroidectomized animals on post-mortem examination. Three days after the start of high dose thyroid hormone treatment, both TRH and TSH $\beta$ transcript levels had fallen to below control values and remained suppressed until 4 days after treatment was withdrawn (Fig. 1a,b), indicating a relatively short biological half life of circulating thyroid hormones (including $\mathrm{T}_{4}$ ) in these animals.

Low dose (18 $\mathrm{ng} \mathrm{T}_{3}$ plus $36 \mathrm{ng} \mathrm{T}_{4} / 100 \mathrm{~g} \mathrm{BW}$ per day) and very low dose thyroid hormone replacement $(1.8 \mathrm{ng}$ $\mathrm{T}_{3}$ plus $3.6 \mathrm{ng} \mathrm{T}_{4} / 100 \mathrm{~g} \mathrm{BW}$ per day) - equivalent to between $1.2 \%$ and $12 \%$ of the dose of $\mathrm{T}_{3}$ and 0.4 to $4 \%$ of the dose of $\mathrm{T}_{4}$ required to normalize circulating TSH and $\mathrm{T}_{4}$ and $\mathrm{T}_{3}$ levels in plasma and tissues (Escobar-Morreale et al. 1995, 1996) was insufficient to diminish raised TRH and TSH $\beta$ transcript levels (Fig. 2a,b).

\section{Pituitary weight changes}

Pituitary wet weight increased by $33 \%$ between days $3-4$ and day 21 of the study (from an average of $5.54 \pm 0.09 \mathrm{mg}$ to $7.37 \pm 0.18 \mathrm{mg}$ ) in keeping with overall somatic growth. There was no significant difference in gain in pituitary weight between thyroidectomized and sham operated animals over this time period (7.29 $\pm 0 \cdot 23 \mathrm{mg}$ vs $7 \cdot 43 \pm 0 \cdot 26 \mathrm{mg}$ at 21 days).

\section{TSH immunohistochemistry}

Under basal conditions, using a standard formaldehyde fixation procedure, $4 \cdot 31 \pm 0 \cdot 15 \%$ of the total parenchymal cells in the anterior pituitary were immunohistochemically identifiable thyrotrophs. Three weeks after surgical thyroidectomy, the number of thyrotrophs appeared to have increased to $6.39 \pm 0.47 \%(P<0.01 ; n=6)$. One week after supraphysiological thyroid hormone replacement, the number of thyrotrophs had decreased to $5 \cdot 48 \pm 0 \cdot 32 \%$. However, cell counts were not corrected for the increase in thyrotroph cell size that occurs after surgical thyroidectomy, and will therefore be an overestimate of changes in thyrotroph cell numbers (Floderus 1944).

\section{Changes in anterior pituitary mitotic and apoptotic activity}

In control (untreated and intact) animals, the prevalence of mitotic figures and apoptotic bodies in the anterior pituitary was $0 \cdot 086 \pm 0 \cdot 013 \%$ and $0 \cdot 036 \pm 0 \cdot 008 \%$ respectively $(n=10$; Fig. $3 \mathrm{a}, \mathrm{b})$, equivalent to an average rate of anterior pituitary cell entry into mitosis of approximately once every 60-70 days (Nolan et al. 1999). There were no significant differences in the prevalence of these trophic markers following surgical thyroidectomy at any time-point up to 28 days after surgery.

Following treatment with a high dose of thyroid hormones beginning 21 days after thyroidectomy, there was a significant increase in mitotic activity that peaked 5 days after the start of treatment at $0 \cdot 231 \pm 0.064 \%$ (Fig. 3a). There was no concurrent, significant increase in apoptotic activity over the same time period. Following withdrawal of thyroid hormone treatment, the prevalence of both mitotic figures and apoptotic bodies dipped below baseline levels although the values did not reach statistical significance compared with sham-operated controls.

To determine whether independent of their specific effects on the hypothalamic-pituitary-thyroid axis, thyroid hormones may be required for anterior pituitary cell proliferation to occur, low dose and very low dose $\mathrm{T}_{4}$ and $\mathrm{T}_{3}$ at $1 \%$ and $0 \cdot 1 \%$ of the treatment dose (less than $5 \%$ of estimated physiological replacement dose) were given for 7 days after surgical thyroidectomy. This resulted in a small, dose-related incremental increase in the mitotic index measured 7 days later (Fig. 4), consistent with a permissive effect of thyroid hormones on mitotic activity in the presence of raised TRH levels.

As the total number of mitotic figures observed at any one time point remained extremely low at a fraction of one percent, it was not possible to, and neither did we expect to be able to, correlate mitotic activity with specific cellular subpopulations with sufficient precision to allow any conclusions to be drawn about the cell type or types involved.

\section{Cumulative mitotic activity measured with BrdU incorporation}

The absence of any overall change in mitotic activity during the seven days after thyroidectomy was confirmed by measuring the cumulative BrdU-labelling index (Fig. 5). Although no significant difference in the number of BrdU-labelled cells was found between thyroidectomized and intact control animals, intact rats treated with a high dose of thyroid hormones over a similar time period showed a significant increase in anterior pituitary cell BrdU-labelling index. The absolute percentages of BrdUlabelled cells measured may be affected by many of the stages of the immunohistochemistry procedure, in particular the characteristics of the primary antibody used. The assay was therefore carried out simultaneously on all sections so that valid comparisons could be drawn between the three experimental groups. 

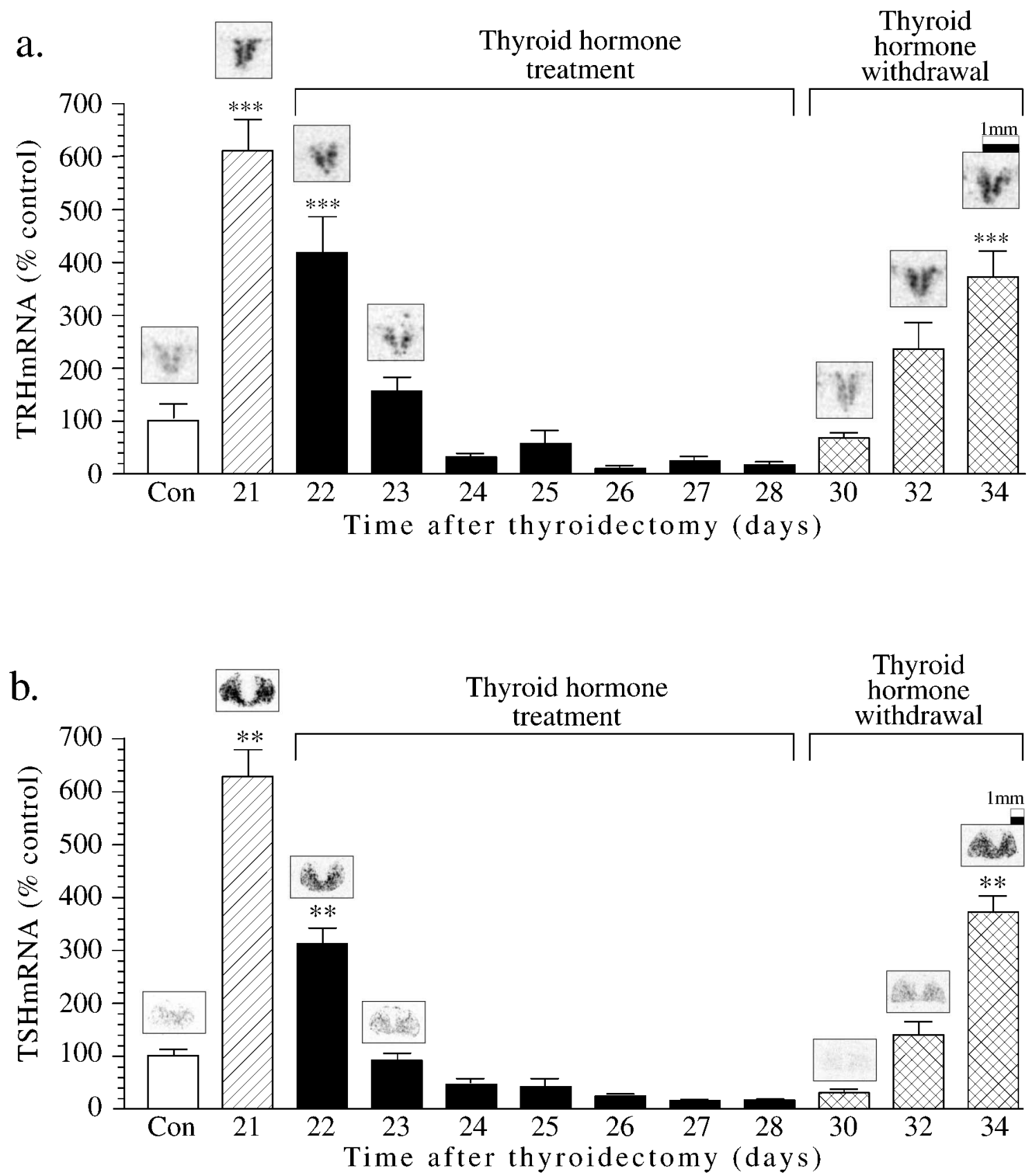

Figure 1 The effects of surgical thyroidectomy, supraphysiological thyroid hormone treatment $\left(1.8 \mu g \mathrm{~T}_{3}\right.$ and $3.6 \mu \mathrm{g} \mathrm{T}_{4}$ per $100 \mathrm{~g}$ BW per day) and thyroid hormone withdrawal on the prevalence of paraventricular TRH transcripts (a) and anterior pituitary TSH $\beta$ transcripts (b). Mean deviation from controls (Con) is shown as $\% \pm$ S.E., $n=4-6 .{ }^{* *} P<0 \cdot 01,{ }^{* * *} P<0 \cdot 001$ compared with controls. Representative autoradiographs of the paraventricular nucleus (a) and pituitary (b) from different groups are shown. The scale bars are $1 \mathrm{~mm}$.

\section{Discussion}

The rate of change in the size of a specific cell population is determined not only by the rate of cell proliferation and differentiation into the compartment of interest, but also by the rate of apoptosis. Real changes in the relative size of pituitary subpopulations are also potentially influenced by transdifferentiation, a direct change from one mature phenotype to another through qualitative changes in hormone production by a dedicated, unihormonal cell. 
a.

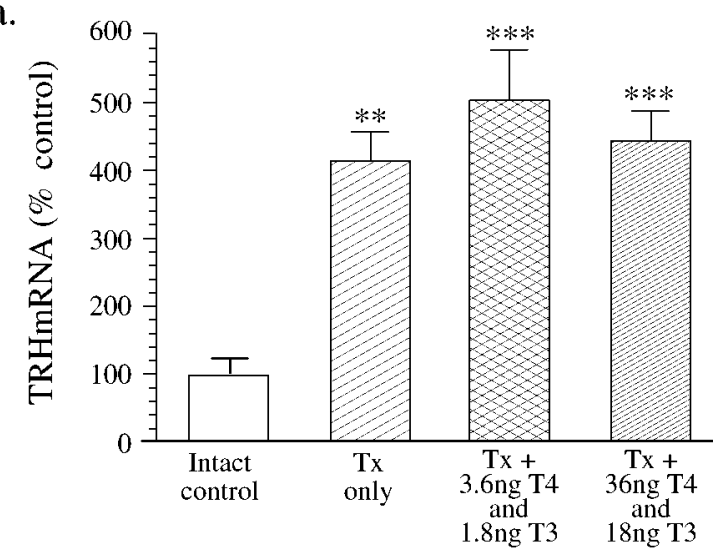

b.

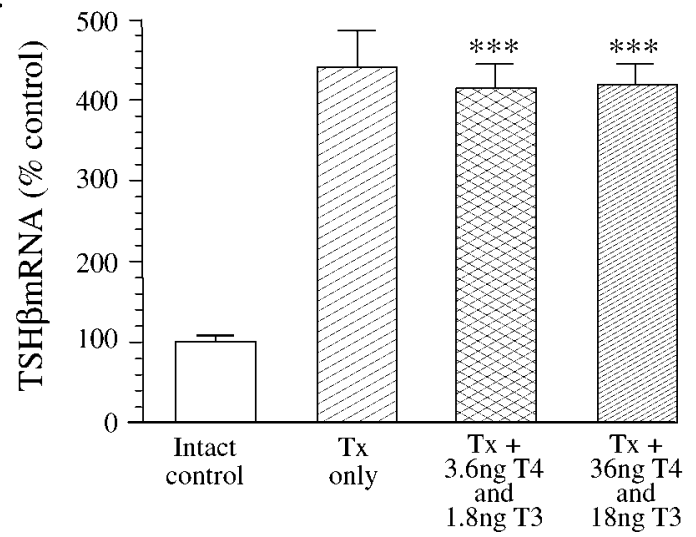

Figure 2 Lack of effect of continual, low dose (subphysiological) thyroid hormone replacement on TRH and TSH $\beta$ transcriptional activity in thyroidectomized (Tx) rats. Low dose and very low dose

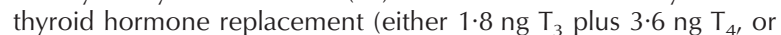
$18 \mathrm{ng} \mathrm{T}_{3}$ plus $36 \mathrm{ng} \mathrm{T}_{4}$ ) was given daily for the week after surgical thyroidectomy. The prevalence of paraventricular TRH transcripts (a) and anterior pituitary TSH $\beta$ transcripts (b) was measured. Mean deviation from controls is shown as $\% \pm$ S.E., $n=5-7$. ${ }^{* *} P<0 \cdot 01$, ${ }^{* * *} P<0 \cdot 001$ compared with controls.

Indeed, thyrosomatotrophs, regarded by some as an intermediate cell in the transdifferentiation between somatotrophs and thyrotrophs, have been demonstrated in both human (Vidal et al. 2000) and rat (Horvath et al. 1990) pituitary in response to protracted hypothyroidism.

In the present study we have shown that surgical thyroidectomy, unlike surgical bilateral adrenalectomy (Nolan et al. 1998, Nolan \& Levy 2001), does not induce an overt increase in anterior pituitary mitotic activity that can be measured morphologically. This was despite a sixfold increase in both pituitary TSH $\beta$ and paraventricular TRH transcript prevalence, and a presumed concomitant increase in pituitary TRH peptide exposure.
These data were further corroborated by the lack of an increase in the cumulative BrdU-labelling index one week after thyroidectomy when compared with the cumulative BrdU-labelling index found in intact controls. In addition, the rate of apoptosis remained at a level indistinguishable from the baseline rate throughout the 3-week period following total thyroidectomy.

The proportion of anterior pituitary immunohistochemically identifiable thyrotrophs was markedly increased when measured three weeks after thyroidectomy. However, larger structures are relatively overrepresented in tissue section as they are more likely to appear and to be counted in multiple sections - a factor exemplified in the extreme by considering overrepresentation in section of a single tennis ball in a box of 1000 table tennis balls. Thus the real increase in prevalence of thyrotrophs per unit volume of the anterior pituitary is likely to be considerably more modest than the absolute percentages measured in this study by direct counting.

Furthermore, although not directly addressed in this study, changes in the number of thyrotrophs that may have resulted from transdifferentiation would be immunohistochemically indistinguishable from quantitative switching in hormone production by bihormonal or pleurihormonal cells. Given the high prevalence of transcriptionally pleurihormonal tumours that clinically lead to hypersecretion of only one hormone (Levy \& Lightman $1988 b, c)$, and the apparent multi-responsiveness of individual anterior pituitary cells to hypothalamic-releasing hormones (Villalobos et al. 1997), it is possible that many cells classified as dedicated single hormone secreting are in fact bihormonal or pleurihormonal but that only one hormone is present at an immunochemically detectable level.

In male rats that have been thyroidectomized 5 months previously, thyroid hormone replacement and exogenous TRH act synergistically to increase the proliferative response in somatotrophs (Quintanar-Stephano \& Valverde 1997). It has also been suggested that $T_{4}$ is required for normal somatotroph proliferation to occur (Quintanar-Stephano et al. 1999). Our results are in agreement with these data in as much as we were able to demonstrate a small but significant increase in mitotic activity beginning two days after the start of supraphysiological thyroid hormone treatment in hypothyroid rats. Once again, the rate of apoptosis remained unchanged throughout the week-long treatment period. Following withdrawal of thyroid hormones, the mitotic index fell rapidly to a level below that found in intact controls. Thus thyroid hormones appear to exert a general permissive effect on mitosis in the thyroidectomized rat anterior pituitary in the presence of high levels of TRH. The addition of very low dose thyroid hormone replacement in thyroidectomized animals (approximately $12 \%$ of the $\mathrm{T}_{3}$ and $4 \%$ of the $\mathrm{T}_{4}$ doses required to 
a.
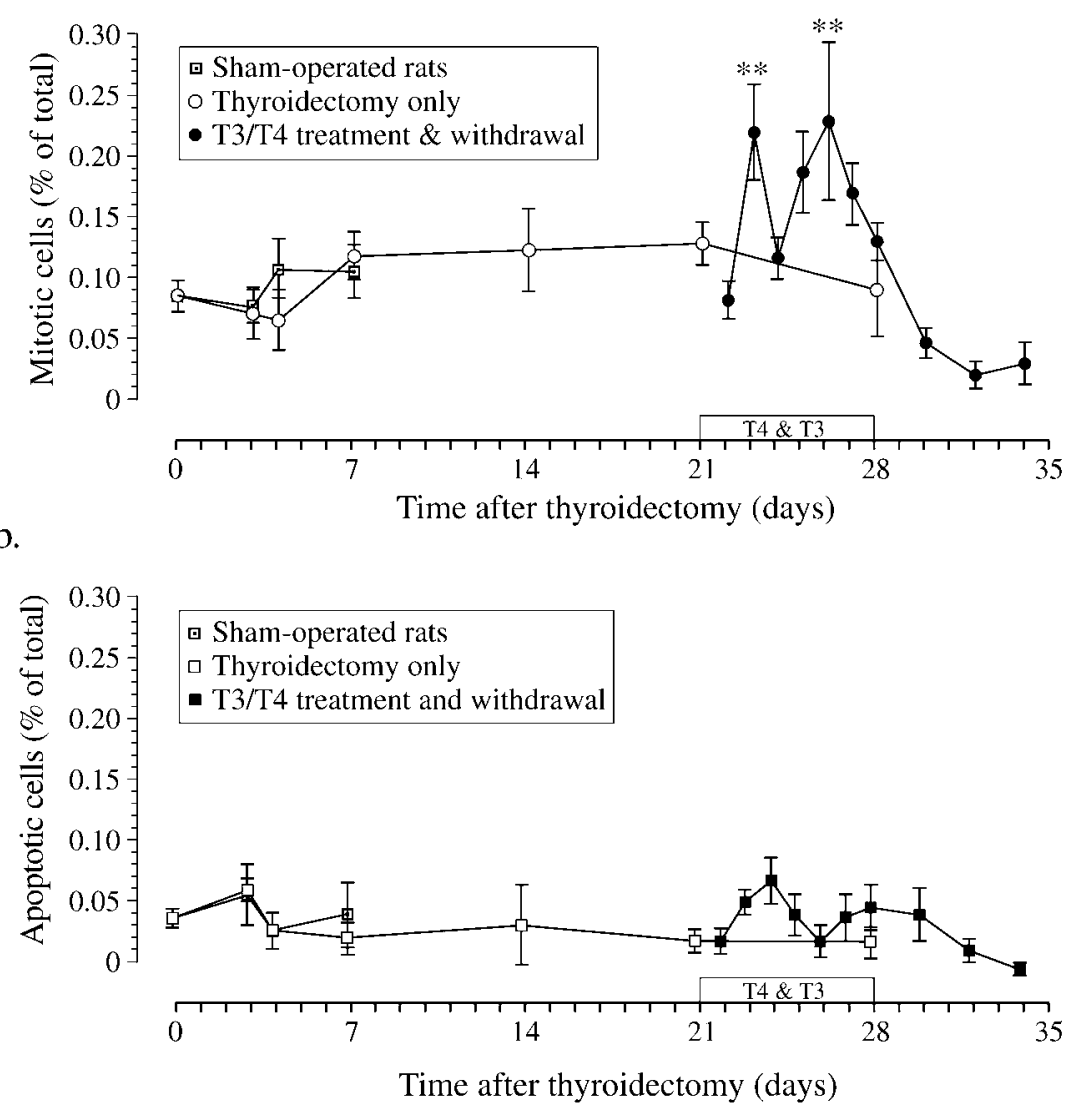

Figure 3 The effects of alterations in thyroid status on anterior pituitary mitotic and apoptotic activity. Changes in the prevalence of mitotic cells (a) and apoptotic cells (b) are shown as a percentage of total anterior pituitary parenchymal cells following surgical thyroidectomy or sham surgery (at time zero), thyroid hormone replacement from day 21 to day 28 and thyroid hormone withdrawal from day 28 to day 35. Values shown are means \pm S.E., $n \geq 6 ;{ }^{* *} P<0 \cdot 01$ compared with controls at time 0 .

maintain circulating and tissue thyroid hormone levels (Escobar-Morreale et al. 1996)) induced a small but significant increase in the prevalence of mitotic figures after one week. Raised levels of TRH are not required to permit thyroid hormone-mediated mitotic effects in the anterior pituitary, however, as supraphysiological levels of thyroid hormones in intact rats also significantly enhanced the anterior pituitary BrdU-labelling index over a period of one week. The data obtained from intact rats also indicate that under euthyroid conditions in young male rats, ambient thyroid hormone levels to some extent constrain pituitary mitotic activity, at least in the short term.

At any one time point the maximum percentage of cells identified as being in mitosis is less than a quarter of one percent, a level that prevents accurate quantification of the cell types involved in proliferation. We were therefore unable to exclude the possibility that thyroidectomy might result in a switch in mitotic activity towards thyrotrophs, with a concurrent reduction in mitotic activity in other cellular subpopulations, such as lactotrophs and somatotrophs (Astier et al. 1980, Stahl et al. 1999) leaving overall mitotic levels unchanged. Unlike the case in humans, particularly females, where hypothyroidism is associated with hyperprolactinaemia and some degree of lactotroph hypertrophy (Pioro et al. 1988, Molitch 1992, Ghannam et al. 1999, Brandle \& Schmid 2000, Kocova et al. 2001, Raber et al. 2003), lactotrophs tend to atrophy post thyroidectomy in rats (Ozawa \& Kurosumi 1993, Kimura \& Furudate 1996). In our study, anterior pituitary prolactin transcripts were reduced during the onset and maintenance of hypothyroidism and returned to control levels or above after the start of thyroid hormone replacement (data not shown).

In summary, we have demonstrated that there is no overall increase in mitotic or apoptotic prevalence in the 


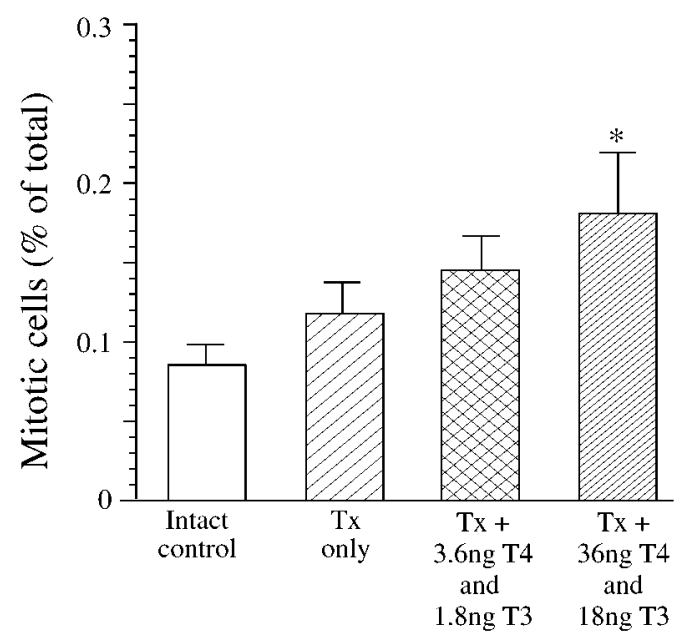

Figure 4 The stimulatory effects of continual, low dose (subphysiological) thyroid hormone replacement on the directly measured prevalence of mitotic cells in thyroidectomized (Tx) rats. Low dose and very low dose thyroid hormone replacement (either $1.8 \mathrm{ng} \mathrm{T}_{3}$ plus $3.6 \mathrm{ng} \mathrm{T}_{4}$, or $18 \mathrm{ng} \mathrm{T}_{3}$ plus $36 \mathrm{ng} \mathrm{T}_{4}$ ) was given daily for a week following surgical thyroidectomy. Values shown are means \pm S.E., $n>5 \leq 10 ;{ }^{*} P<0 \cdot 05$.

male rat anterior pituitary during the immediate period after surgical thyroidectomy despite an apparent increase in the number of thyrotrophs. Thyroid hormones appear to be permissive for pituitary mitotic responses but increased TRH alone has no effect. Finally, our results suggest that under basal conditions, ambient thyroid hormone levels restrain anterior pituitary mitotic activity.

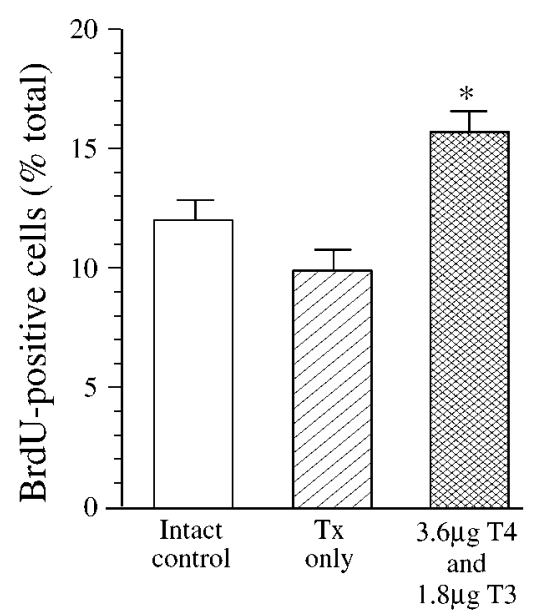

Figure 5 The cumulative effects of supraphysiological thyroid hormone treatment on anterior pituitary BrdU-labelling index in intact animals after 7 days. Intact rats were given $1.8 \mu \mathrm{g} \mathrm{T}_{3}, 3.6 \mu \mathrm{g}$ $\mathrm{T}_{4}$ and $20 \mathrm{mg} \mathrm{BrdU}$ per $100 \mathrm{~g} \mathrm{BW}$ per day, daily for 7 days, prior to analysis of BrdU-labelling index. Means \pm S.E. are shown, $n=4-5$; ${ }^{\star} P<0.05$ compared with controls. Tx, thyroidectomized.

\section{Funding}

We are grateful to the Wellcome Trust for providing financial support for this study.

\section{References}

Astier HS, DeFesi CR \& Surks MI 1980 Kinetics of deoxyribonucleic acid synthesis and duplication of thyrotrophs and somatotrophs during development of hypothyroidism and L-tri-iodothyronine treatment of hypothyroid rats. Journal of Clinical Endocrinology and Metabolism 106 1537-1548.

Brandle M \& Schmid C 2000 Galactorrhoea and pituitary mass: a typical prolactinoma? Postgraduate Medical Journal 76 232-234.

Brugal G, Dye R, Krief B, Chassery J-M, Tanke H \& Tucker JH 1992 HOME: highly optimized microscope environment. Cytometry 13 109-116.

Cameron HA \& McKay RD 1999 Restoring production of hippocampal neurons in old age. Nature Neuroscience 2 894-897.

DeFesi CR, Astier HS \& Surks ML 1979 Kinetics of thyrotrophs and somatotrophs during development of hypothyroidism and L-tri-iodothyronine treatment of hypothyroid rats. Endocrinology 104 1172-1180.

Escobar-Morreale HF, Obregon MJ, Escobar del Rey F \& Morreale de Escobar G 1995 Replacement therapy for hypothyroidism with thyroxine alone does not ensure euthyroidism in all tissues, as studied in thyroidectomized rats. Journal of Clinical Investigation 96 $2828-2838$.

Escobar-Morreale HF, del Rey FE, Obregon MJ \& de Escobar GM 1996 Only the combined treatment with thyroxine and tri-iodothyronine ensures euthyroidism in all tissues of the thyroidectomized rat. Endocrinology 137 2490-2502.

Floderus S 1944 Untersuchungen über den Bau der menschlichen Hypophyse mit besonderer Berucksichtigung der quantitativen mikromorphologischen Verhältnisser. Acta Pathologica Microbiologica Scandinavica Supplement $\mathbf{5 3} 276$.

Ghannam NN, Hammami MM, Muttair Z \& Bakheet SM 1999 Primary hypothyroidism-associated TSH-secreting pituitary adenoma/hyperplasia presenting as a bleeding nasal mass and extremely elevated TSH level. Journal of Endocrinological Investigation 22 419-423.

Horvath E, Lloyd RV \& Kovacs K 1990 Propylthiouracyl-induced hypothyroidism results in reversible transdifferentiation of somatotrophs into thyroidectomy cells. A morphological study of the rat pituitary including immunoelectron microscopy. Laboratory Investigation 63 511-520.

Kimura T \& Furudate S 1996 Pituitary GH and prolactin deficiency and testis enlargement in hypothyroid rats caused by goitrogen methimazole. Experimental Animals/Japanese Association for Laboratory Animal Science 45 369-375.

Kocova M, Netkov S \& Sukarova-Angelovska E 2001 Pituitary pseudotumor with unusual presentation reversed shortly after the introduction of thyroxine replacement therapy. Journal of Pediatric Endocrinology and Metabolism 14 1665-1669.

Levy A \& Lightman SL 1988a Quantitative in-situ hybridization histochemistry in the rat pituitary gland: effect of bromocriptine on prolactin and pro-opiomelanocortin gene expression. Journal of Endocrinology 118 205-210.

Levy A \& Lightman SL 1988 b Quantitative in-situ hybridization histochemistry of anterior pituitary hormone mRNA species in human pituitary adenomas. Acta Endocrinologica 119 397-404.

Levy A \& Lightman SL 1988c Quantitative in-situ hybridization histochemistry studies on growth hormone $(\mathrm{GH})$ gene expression in acromegalic somatotrophs: effects of somatostatin, GH-releasing factor and cortisol. Journal of Molecular Endocrinology 1 19-26. 
Levy A \& Lightman SL 2003 Molecular defects in the pathogenesis of pituitary tumors. Frontiers in Neuroendocrinology 24 94-127.

Molitch ME 1992 Pathologic hyperprolactinemia. Endocrinology and Metabolism Clinics of North America 21 877-901.

Nicholas WC \& Russell WF 2000 Primary hypothyroidism presenting as a pituitary mass. Journal of the Mississippi State Medical Association 41 511-514.

Nolan LA \& Levy A 2001 Anterior pituitary trophic responses to dexamethasone withdrawal and repeated dexamethasone exposures. Journal of Endocrinology 169 263-270.

Nolan LA \& Levy A 2003 Temporally sensitive trophic responsiveness of the adrenalectomized rat anterior pituitary to dexamethasone challenge: relationship between mitotic activity and apoptotic sensitivity. Endocrinology 144 212-219.

Nolan LA, Kavanagh E, Lightman SL \& Levy A 1998 Anterior pituitary cell population control: basal cell turnover and the effects of adrenalectomy and dexamethasone treatment. Journal of Neuroendocrinology 10 207-215.

Nolan LA, Lunness HR, Lightman SL \& Levy A 1999 The effects of age and spontaneous adenoma formation on trophic activity in the rat pituitary gland: a comparison with trophic activity in the human pituitary and in human pituitary adenomas. Journal of Neuroendocrinology 11 393-401.

Ozawa H \& Kurosumi K 1993 Morphofunctional study on prolactin-producing cells of the anterior pituitaries in adult male rats following thyroidectomy, thyroxine treatment and/or thyrotropin-releasing hormone treatment. Cell and Tissue Research 272 41-47.

Pioro EP, Scheithauer BW, Laws ERJ, Randall RV, Kovacs KT \& Horvath E 1988 Combined thyrotroph and lactotroph cell hyperplasia simulating prolactin-secreting pituitary adenoma in long-standing primary hypothyroidism. Surgical Neurology 29 218-226.
Quintanar-Stephano A \& Valverde C 1997 Mitogenic effects of thyroxine and TRH on thyrotrophs and somatotrophs of the anterior pituitary gland in thyroidectomized rats. Journal of Endocrinology 154 149-153.

Quintanar-Stephano A, Valverde-R C \& Kovacs K 1999 Mitotic counts in rat adenohypophysial thyrotrophs and somatotrophs: effects of short-term thyroidectomy, thyroxine, and thyrotropin-releasing hormone. Endocrine Pathology 10 335-341.

Raber W, Gessl A, Nowotny P \& Vierhapper H 2003 Hyperprolactinaemia in hypothyroidism: clinical significance and impact of TSH normalization. Clinical Endocrinology 58 185-191.

Shi Z-X, Levy A \& Lightman SL 1994 Thyroid hormone-mediated regulation of corticotrophin-releasing hormone mRNA in the rat. Endocrinology 134 1577-1580.

Shu S, Ju G \& Fan L 1988 The glucose oxidase-DAB-nickel method in peroxidase histochemistry of the nervous system. Neuroscience Letters 85 169-171.

Stahl JH, Kendall SK, Brinkmeier ML, Greco TL, Watkins-Chow DE, Campos-Barros A, Lloyd RV \& Camper SA 1999 Thyroid hormone is essential for pituitary somatotropes and lactotropes. Endocrinology 140 1884-1892.

Vidal S, Horvath E, Kovacs K, Cohen SM, Lloyd RV \& Scheithauer BW 2000 Transdifferentiation of somatotrophs to thyrotrophs in the pituitary of patients with protracted primary hypothyroidism. Virchows Archive 436 43-51.

Villalobos C, Nunez L, Frawley LS, Garcia-Sancho J \& Sanchez A 1997 Multi-responsiveness of single anterior pituitary cells to hypothalamic-releasing hormones: a cellular basis for paradoxical secretion. PNAS 94 14132-14137.

Received in final form 7 October 2003

Accepted 22 October 2003 